\title{
AVALIAÇÃo de PROTOCOLO PARA OBTENÇÃo DE MUDAS MICROPROPAGADAS DE BANANEIRA CV. PRATA-ANÃ (SUBGRUPO AAB) ${ }^{1}$
}

\author{
MARIA EUGÊNIA LISEI DE SÁ e MARCELO FIDELES BRAGA³
}

\begin{abstract}
RESUMO - O trabalho teve como objetivo avaliar um sistema de micropropagação para a cultivar Prata-Anã, observando-se os principais fatores de eficiência e limitação no processo produtivo da muda. Os explantes foram estabelecidos em meio nutritivo MS, suplementado com $5 \mathrm{mg} / \mathrm{L}$ de BAP (benzilaminopurina) e $30 \mathrm{~g} / \mathrm{L}$ de sacarose solidificado com $8 \mathrm{~g} / \mathrm{L}$ de ágar e $\mathrm{pH}$ ajustado em 5,7. A fase de multiplicação foi composta pelo mesmo meio de cultura e a de enraizamento constituída pela metade da concentração dos sais de MS e de sacarose, sem regulador de crescimento. Perdas por contaminação bacteriana foram maiores durante o estabelecimento in vitro e por fungos, nos dois últimos subcultivos. As maiores taxas de multiplicação ocorreram entre o $4^{0}$ e o $5^{0}$ subcultivos e, ao final do processo, observou-se maior proporção de brotos na classe entre 30 e $60 \mathrm{~mm}$. Com relação à eficiência da utilização da mão-de-obra no laboratório, observou-se que o processamento diário de frascos por operador foi baixo nas fases de estabelecimento, primeiro subcultivo e enraizamento, quando comparado com as fases de multiplicação exponencial dos explantes. Apesar de não terem sido constatadas perdas na fase de aclimatação, foi observada a ocorrência de $1 \%$ do total das plântulas com anomalias morfológicas.
\end{abstract}

Termos para indexação: micropropagação, Musa sp..

\section{EVALUATION OF A PROTOCOL TO OBTAIN MICROPROPAGATED PLANTLETS OF BANANA CV. PRATA-ANÃ (SUBGROUP AAB)}

\begin{abstract}
The purpose of this work was to evaluate a micropropagation system to cultivar Prata-Anã, observing the main factors of efficiency and limitation in the plantlet production process. The explants were established in the medium MS, supplemented with $5 \mathrm{mg} / \mathrm{L}$ BAP (benzilaminopurine), $30 \mathrm{~g} / \mathrm{L}$ sucrose, $8 \mathrm{~g} / \mathrm{L}$ agar and $\mathrm{pH} 5.7$. The bud multiplication was carried out in the same medium described above and the plantlet rooting phase was done with half concentration of salt and sucrose, without plant growth regulator. Losses by bacterial contamination were higher during the in vitro establishment and by fungus in the last two subcultures. The highest multiplication rates occurred between the fourth and the fifth subcultures and at the end of the process it was observed higher proportion of plantlets between 30 and $60 \mathrm{~mm}$. In relation to the efficiency of the number of glasses processed per operator in the laboratory it was low in the establishment, phase first subculture and rooting, when compared with the exponential multiplication phase of the explants. Even though it was noticed losses in the acclimatization phase, it was observed the occurrence of $1 \%$ of plantlets with morphological variation.
\end{abstract}

Index terms: micropropagation, Musa sp..

A banana (Musa spp.) é a fruteira mais plantada no Brasil , respondendo por $17 \%$ da produção mundial ( $2^{0}$ produtor $)$, porém com apenas $1 \%$ de participação no comércio internacional (140 exportador) (Alves, 1997; Agrianual, 1998). Apesar de predominarem as variedades do subgrupo Cavendish no mercado internacional, no Brasil, as bananas do tipo Prata são as mais preferidas (Mascarenhas, 1999). A cultivar Prata-Anã, que é hoje produzida em diversos Estados brasileiros, tem-se destacado no cenário nacional como prioridade para estudos nos perímetros irrigados da região Norte de Minas Gerais garantindo, assim, o sucesso deste empreendimento nessa região (Souto et al., 1999).

A produtividade média de banana no Brasil é considerada baixa, inferior a $10 \mathrm{t} / \mathrm{ha} / \mathrm{ano}$, principalmente devido à falta de cultivares melhoradas, condução e manejo inadequados dos plantios e, principalmente, à incidência de doenças e pragas
(Pereira et al., 1999). O grande crescimento da bananicultura, ocorrido nos últimos anos, acarretou uma forte demanda por mudas, muitas vezes de origem e qualidades duvidosas (Silva et al., 1999). Tendo em vista que o sistema de propagação convencional é lento e possui baixo rendimento, recentes estudos têm mostrado que a adoção da micropropagação é uma boa alternativa (Souza et al., 1997). Além de se alcançarem taxas de multiplicação diversas vezes mais elevadas que aquelas obtidas com os métodos convencionais, a micropropagação da bananeira oferece ainda a possibilidade para a produção comercial de mudas (Borges et al., 1997), aumentando de maneira considerável o número de plantas livres de pragas e doenças como o Mal-doPanamá (Fusarium oxysporium f. sp. Cubense), Moko (Pseudomonas solanacearum), Sigatoka-negra (Mycosphaerella fijensis var. difformis), nematóide (Radopholus similis) e a Brocado-rizoma ( Cosmopolites sordidus), dentro de um curto espaço

1 (Trabalho 026/2001). Recebido: 30/01/2001. Aceito para publicação: 25/10/2001.

2 Bióloga, M.Sc., Pesquisadora Biotecnologia Vegetal, EPAMIG/CTTP, C.P. 351, 38001-970, Uberaba-MG, E-mail: eugeniaepamig@mednet.com.br 3 Engenheiro Agrônomo, M. Sc., Pesquisador Fruticultura, EPAMIG/CTTP, C. O. 351, 38001-970, Uberaba - MG. 
de tempo (Lameira et al., 1990).

Grande parte dos inúmeros trabalhos relacionados à obtenção de mudas de bananeira in vitro têm enfocado, principalmente, o tipo de explante, composição dos meios de cultura e condições físicas do ambiente que propiciam maiores taxas de multiplicação, assim como métodos distintos para o enraizamento (Lameira et al., 1990; Domingues et al., 1995; Oliveira \& Machado, 1997), sem considerar outros fatores como mão-de-obra e freqüência de tamanho de brotos no final do enraizamento . O aprimoramento constante dos processos de multiplicação in vitro e o controle de qualidade das mudas, aliado à redução de custos, têm sido essenciais para a sua aceitação no mercado (Assis et al., 2000). Portanto, o objetivo do presente trabalho foi avaliar um sistema de micropropagação para a cultivar Prata-Anã, observando os principais fatores de eficiência e limitação no processo produtivo da muda.

Rizomas de bananeira tipo chifrinho, cv. Prata-Anã, provenientes do bananal da Escola Agrotécnica Federal de Uberaba-MG, foram retirados em dois períodos distintos, sendo o primeiro constituído de 100 unidades, denominado família SA e o segundo, contendo a mesma quantidade, identificado como família SBC. Desses, foram extraídos os explantes contendo a gema apical. Em condições assépticas, estes foram desinfestados com solução de álcool $70 \%$, por 1 min e, em seguida, imersos em solução de hipoclorito de sódio a $2 \%$, por 10 min, sendo então, lavados 4 vezes com água destilada e autoclavada. Posteriormente, cada explante teve seu tamanho reduzido para $0,5 \mathrm{~cm}$ de tecido de rizoma na base, $1 \mathrm{~cm}$ de primórdios foliares e $1 \mathrm{~cm}$ de diâmetro, sendo então estabelecido em meio de cultura, durante 30 dias. Do estabelecimento ao $5^{\circ}$ subcultivo de multiplicação, utilizou-se o meio MS (Murashige \& Skoog, 1962) suplementado com $5 \mathrm{mg} / \mathrm{L}$ de benzilaminopurina (BAP) e $30 \mathrm{~g} / \mathrm{L}$ de sacarose, gelificado com $8 \mathrm{~g} / \mathrm{L}$ de ágar. No enraizamento, utilizou-se um meio com $50 \%$ dos sais minerais do MS mais $15 \mathrm{~g} /$
L de sacarose e $8 \mathrm{~g} / \mathrm{l}$ de ágar, sem BAP. O pH dos meios foi ajustado para 5,7. Em cada fase de cultivo, foram avaliados o desempenho do processamento diário de frascos por operador, assim como os índices de contaminação e o rendimento de explantes em cada subcultura. No final da fase de enraizamento, foram avaliados o comprimento médio e número de brotos ( $\geq 10 \mathrm{~mm}$ ). As plântulas obtidas foram transplantadas e mantidas em estufa com nebulização duas vezes por dia e $60 \%$ de sombreamento, sendo gradativamente submetidas às condições ambientais.

Em ambas as famílias, verifica-se um menor processamento diário de frascos por operador nas subculturas 11 e 21, pois cada frasco das subculturas anteriores (10 e 20) originou apenas 2 nesta fase, uma vez que seus respectivos explantes foram divididos ao meio (Tabela 1). Neste caso, a mãode-obra ficou ociosa, pois o número total de frascos não ocupou toda capacidade produtiva dos operadores. Do segundo ao quinto subcultivos (12-15) da família SA e no terceiro e quarto subcultivos da família SBC, observa-se um incremento no processamento diário do número de frascos, cujas fases correspondem a um crescimento exponencial dos explantes. Do ponto de vista econômico, esta otimização é importante para diluir o custo final da muda. Pode-se notar um ligeiro decréscimo deste número na fase de enraizamento (16 e 26), pois a individualização das plântulas requer uma operação mais cautelosa e há maior número de explantes por frasco, neste caso, quatro. Planilhas de custo de diversos laboratórios de cultura de tecidos têm mostrado que os itens de mão-de-obra e material de consumo compõem a maior parte do custo total da operação (Anciães \& Cassiolato, 1985, citado por Seregen, 1995).

$\mathrm{Na}$ Tabela 2, observa-se que as porcentagens de contaminação por bactérias ocorreram em maiores taxas durante a fase de estabelecimento in vitro dos explantes (10 e 20), uma vez que as matrizes foram provenientes diretamente do campo, onde a planta está exposta a todo tipo de intempérie. Este nível

TABELA 1 - Desempenho do processamento diário de frascos de entrada ( ou seja, que entraram para serem processados) por pessoa (Entpe), em duas famílias SA e SBC, de bananeira cv. Prata-Anã. Uberaba-MG, 1999

\begin{tabular}{ccccc}
\hline Fases & S A & Entpe & S BC & Entpe \\
\hline Estabelecimento & 10 & 12,00 & 20 & 25,00 \\
M ultiplicação & 11 & 11,67 & 21 & 11,67 \\
& 12 & 26,50 & 22 & 14,50 \\
& 13 & 22,67 & 23 & 29,75 \\
Enraizamento & 14 & 28,25 & 24 & 25,00 \\
& 15 & 24,46 & 25 & 13,50 \\
\hline
\end{tabular}

${ }^{1}$ : número de repicagens diárias avaliadas

TABELA 2 - Percentual de ocorrência de frascos contaminados ao longo das subculturas, em duas famílias SA e SBC, de bananeira cv. Prata-Anã. Uberaba-MG, 1999

\begin{tabular}{|c|c|c|c|c|c|c|}
\hline Fases & SA & $\begin{array}{c}\text { Fungos } \\
\%\end{array}$ & $\begin{array}{c}\text { Bactérias }^{1} \\
\%\end{array}$ & SBC & $\begin{array}{c}\text { Fungos } \\
\%\end{array}$ & $\begin{array}{c}\text { Bactérias }^{1} \\
\%\end{array}$ \\
\hline Estabelecimento & 10 & 1,39 & 48,61 & 20 & - & 36,84 \\
\hline Multiplicação & 11 & - & 7,24 & 21 & - & 3,22 \\
\hline & 12 & - & - & 22 & - & - \\
\hline & 13 & 0,42 & 0,42 & 23 & 0,94 & - \\
\hline & 14 & 0,15 & - & 24 & 2,42 & - \\
\hline & 15 & 1,14 & 0,08 & 25 & 6,25 & - \\
\hline Enraizamento & 16 & 3,02 & 0,45 & 26 & 0,76 & 0,13 \\
\hline
\end{tabular}

${ }^{1}$ : alguns frascos apresentaram ambos os tipos de contaminantes. 


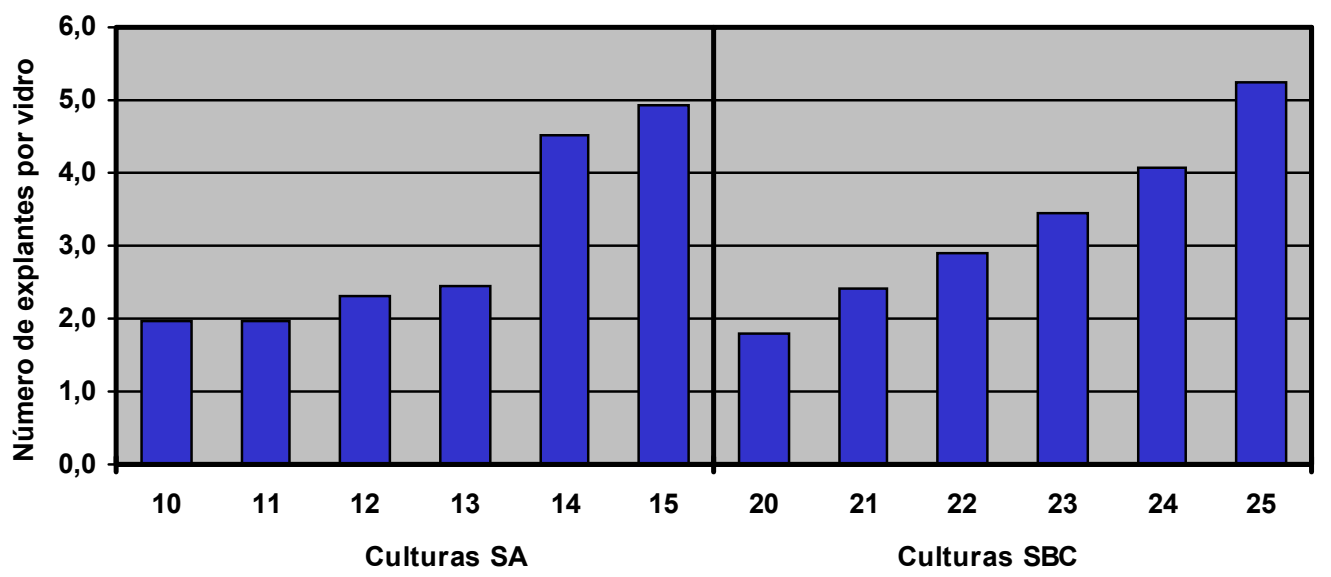

$\square$ Taxa de multiplicação de explantes

FIGURA 1 - Taxa de multiplicação de explantes em cada subcultura de bananeira cv. Prata-Anã. Uberaba-MG, 1999.

SA

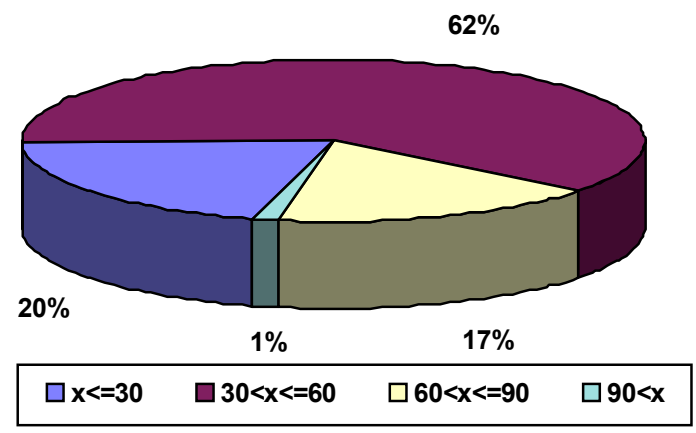

SBC

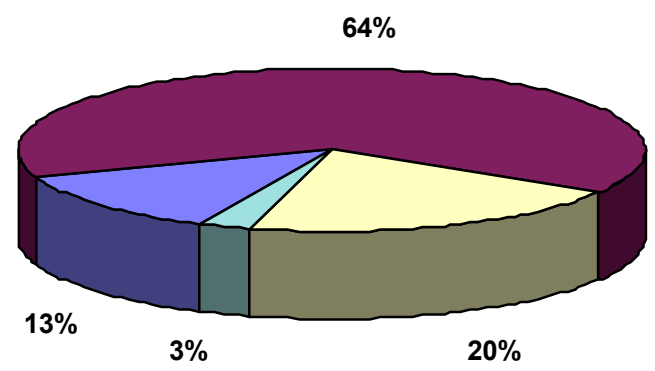

FIGURA 2 - Porcentagem das diferentes classes de tamanho de brotos de bananeira cv. Prata-Anã nas famílias SA e SBC, no final da fase de enraizamento. Uberaba-MG, 1999.

foi decrescendo drasticamente ao longo das subculturas, até desaparecer totalmente a partir do $2^{0}$ subcultivo da família SBC. Houve um pequeno acréscimo de contaminação bacteriana na fase de enraizamento da família SA (16), muito provavelmente causada por deficiência no processo de manipulação, uma vez que, concomitantemente, ocorreu uma alta taxa de contaminação por fungo, ou até mesmo por bactérias endógenas que estavam quiescentes. Estes elevados índices de perdas durante a fase de estabelecimento dos explantes de bananeira in vitro estão de acordo com os resultados obtidos por Oliveira \& Silva, 1997; Oliveira \& Machado, 1997; Oliveira et al., 1999. Devido ao grande volume de frascos com plântulas envolvidos em uma biofábrica, um surto de contaminação pode causar grande perda em pouco tempo, podendo ocorrer em qualquer fase do processo (Lee et al., 1995).

Na Figura 1, nota-se que as maiores taxas de multiplicação ocorreram no quarto e quinto subcultivos da família SA e do terceiro ao quinto subcultivos, em ambas, da família SBC. A literatura cita que taxas mais elevadas de multiplicação ocorrem entre o $2^{0}$ e o $6^{0}$ subcultivo, quando os explantes já se encontram mais adaptados às condições in vitro (Oliveira \& Silva, 1997; Oliveira et al., 1999). Classificando as brotações por tamanho (Figura 2 ), verifica-se que existem diferenças significativas entre as classes distintas. Em ambas as famílias SA e SBC, ocorreu maior proporção de brotos na faixa de 30 a $60 \mathrm{~mm}$ (62 e 64\%, respectivamente) e menor ocorrência de brotos maiores que $90 \mathrm{~mm}, 1 \%$ e $3 \%$, respectivamente

Além das contaminações, foram descartados explantes com presença de calo, uma vez que estes podem levar à obtenção de plântulas fora-do-padrão (Scowcroft, 1984; George \& Sherrington, 1984; Domingues et al., 1995). Apesar destas medidas, durante a aclimatação, foi encontrado um total de 144 plantas $(1 \%)$ com anomalias morfológicas que foram interpretadas como possíveis variações somáticas originárias nas duas famílias. Esta porcentagem é razoável, uma vez que estes níveis não devem ultrapassar 5\% (Israeli et al., 1991).

Não foram constatadas perdas na aclimatação, pois estando a maioria das plântulas entre 30 e $60 \mathrm{~mm}$ de comprimento, isto conferiu maior facilidade de manuseio e uniformidade no plantio.

1. O protocolo empregado foi eficiente para a multiplicação in vitro de bananeira, cv. Prata-Anã.

2. A performance da mão-de-obra nas subculturas foi baixa, necessitando de estudos para melhorar o rendimento dos 
operadores.

3. A grande ocorrência de contaminações bacterianas, supostamente de origem endógena, sugere um melhor estudo neste tema.

4. A taxa de multiplicação de brotos manteve-se satisfatória, estando de acordo com os índices alcançados em outros trabalhos desenvolvidos com o gênero Musa.

5. O comprimento de brotos entre 30 e $60 \mathrm{~mm}$, ao final da fase de enraizamento, conferiu maior vigor, facilidade de manuseio e uniformidade das plântulas durante o transplantio para casa de vegetação.

\section{REFERÊNCIAS BIBLIOGRÁFICAS}

AGRIANUAL 98. Anuário Estatístico da Agricultura Brasileira. 1998.481p.

ASSIS, M. de; PAIVA, M.; ARAMANI, O.C. Micropropagação de plantas: histórico de uma empresa comercial. Informe Agropecuário, Belo Horizonte, v.21, n.204, p.124-126, 2000.

ALVES, E.J., org. A cultura da banana: aspectos técnicos, sócio econômicos e agroindustriais. Brasília: Embrapa-SPI/Cruz das Almas: Embrapa-CNPMF, 1997. 585p.

BORGES, A.L.; ALVES, E.J.; SILVA, S. de O. e SOUZA, L. da S.; MATOS, A.P. de; FANCELLI, M.; OLIVEIRA, A.M.G.; CORDEIRO, Z.J.M.; SILVEIRA, J.R.S.; COSTA, D. da C.; MEDINA, V.M.; OLIVEIRA, S.L. de; SOUZA, J. da S.; OLIVEIRA, R.P. de; CARDOSO, C.E.L.; MATSUURA, F.C.A.U.; ALMEIDA, C.O. de. O cultivo da banana. Cruz das Almas: EMBRAPACNPMF, 1997. 109p. (EMBRAPA-CNPMF. Circular Técnica, 27)

DOMINGUES, E.T.; TULMANN NETO, A.; MENDES, B.M.J. Cultura de ápices caulinares de Musa sp., var. Maçã: estabelecimento, micropropagação e enraizamento in vitro. Scientia Agrícola, Piracicaba, v.52, n.2, p.387-394, 1995.

GEORGE, E.F.; SHERRINGTON, P.D. Plant propagation by tissue culture. In: EXEGENETICS. Handbook and directory of commercial laboratories. London, p.51-78, 1984.

ISRAELI, Y.; REUVENI, O.; LAHAV, E. Qualitative aspects of somaclonal variations in banana propagated by in vitro techniques. Scientia Horticulturae, Amsterdam, v.48, p.71-77, 1991.

LAMEIRA, O.A.; PINTO, J.E.B.P.; PASQUAL, M. Pesquisa Agropecuária Brasileira, Brasília, v.25, n.11,p.1613-1617, 1990.

LEE, T.S.G.; PICOLLO, L.T.; MENEGHIN, S.P.; ARAUJO, S.M.S.S. Biofábrica: produção industrial de plantas in vitro. In: LEE, T.S.G. (ed.). Biofábrica: produção industrial de plantas in vitro. Araras. Universidade Federal de São Carlos, 1995, p.9-17.
MASCARENHAS, G.C.C. Banana: comercialização e mercados. Informe Agropecuário, Belo Horizonte, v.20, n.196, p.97-108, jan/ fev.1999.

MURASHIGE, T.; SKOOG, F. A revised medium from rapid growth and bioassay with tobacco tissue cultures. Phisiology Plantarum, Copenhagem, v.15, p.473-497, 1962.

OLIVEIRA, R. P.; MACHADO, C.L. Avaliação de protocolo de micropropagação massal em bananeira do subgrupo Prata (Musa spp., Grupo AAB). Revista Brasileira de Fruticultura, Cruz das Almas, v.19,n.2, p.221-226, 1997.

OLIVEIRA, R. P.; SILVA, S.O. Avaliação da micropropagação comercial em bananeira. Pesquisa Agropecuária Brasileira, Brasília, v.32, n.4, p.415-420, 1997.

OLIVEIRA, R. P.; SILVEIRA, D.G.; SILVA, K.M.; VILARINHOS, A.D . Avaliação da micropropagação de genótipos diplóides, triplóides e tetraplóides de bananeira empregando protocolo utilizado em laboratórios comerciais. Revista Brasileira de Fruticultura, Jaboticabal, v.21,n.3,p.269-273, 1999.

PEREIRA, L.V.; CORDEIRO,Z.J.M.; FIGUEIRA, A.R.; HINZ, R.H.; MATOS, A.P. Doenças da bananeira. Informe Agropecuário, Belo Horizonte, v.20, n.196, p.37-47, jan/fev.1999.

SCOWCROFT, W.R. Genetic variability in tissue culture, impact on germoplasm conservation and utilization. In: INTERNATIONAL BOARD FOR PLANT GENETIC RESOURCES MEETING, Rome: IBPGR, 1984, p.41.

SEGEREN, M.I. Micropropagação in vitro de flores e plantas ornamentais. In: LEE, T.S.G. (ed.). Biofábrica: produção industrial de plantas in vitro. Araras. Universidade Federal de São Carlos, 1995, p. 45-51.

SILVA, C.R.R.; SOUTO, R;F.; MENEGUCCI, J.L.P. Propagação da bananeira. Informe Agropecuário, Belo Horizonte, v.20, n.196, p.16-20, jan/fev.1999.

SOUTO, R.F.; RODRIGUES, M.G.V.; RUGGIERO, C.; MENEGUCCI, J.L.P. Novas Perspectivas em sistemas de implantação, condução e práticas de manejo da bananeira. Informe Agropecuário, Belo Horizonte, v.20, n.196, p.10-15, jan/ fev.1999.

SOUZA, A. S.; DANTAS, J.L.L.; SOUZA, F.V.D.S.; CORDEIRO, Z.J.M.; SILVA NETO, S.P. da. Propagação. In: ALVES, E.J. (org.) A cultura da banana: aspectos técnicos, socioeconômicos e agroindustriais. Brasília: Embrapa-SPI/Cruz das Almas: EmbrapaCNPMF, 1997.p.151-195. 